\title{
Solubility of Cinnarizine in (Transcutol + Water) Mixtures: Determination, Hansen Solubility Parameters, Correlation, and Thermodynamics
}

\author{
Faiyaz Shakeel ${ }^{1, *(1)}$, Mohsin Kazi ${ }^{1}\left(\mathbb{D}\right.$, Fars K. Alanazi $^{1}\left(\mathbb{D}\right.$ and Prawez Alam ${ }^{2}$ \\ 1 Department of Pharmaceutics, College of Pharmacy, King Saud University, Riyadh 11451, Saudi Arabia; \\ mkazi@ksu.edu.sa (M.K.); afars@ksu.edu.sa (F.K.A.) \\ 2 Department of Pharmacognosy, College of Pharmacy, Prince Sattam Bin Abdulaziz University, \\ Al-Kharj 11942, Saudi Arabia; prawez_pharma@yahoo.com \\ * Correspondence: faiyazs@fastmail.fm
}

Citation: Shakeel, F.; Kazi, M.; Alanazi, F.K.; Alam, P. Solubility of Cinnarizine in (Transcutol + Water) Mixtures: Determination, Hansen Solubility Parameters, Correlation, and Thermodynamics. Molecules 2021 26, 7052. https://doi.org/10.3390/ molecules 26227052

Academic Editor: Jose C. Corchado

Received: 31 October 2021

Accepted: 20 November 2021

Published: 22 November 2021

Publisher's Note: MDPI stays neutral with regard to jurisdictional claims in published maps and institutional affiliations.

Copyright: (C) 2021 by the authors. Licensee MDPI, Basel, Switzerland. This article is an open access article distributed under the terms and conditions of the Creative Commons Attribution (CC BY) license (https:// creativecommons.org/licenses/by/ $4.0 /)$.

\begin{abstract}
Between 293.2 and $313.2 \mathrm{~K}$ and at $0.1 \mathrm{MPa}$, the solubility of the weak base, cinnarizine (CNZ) (3), in various \{Transcutol-P (TP) (1) + water (2)\} combinations is reported. The Hansen solubility parameters (HSP) of CNZ and various $\{(\mathrm{TP})(1)+$ water (2) $\}$ mixtures free of CNZ were also predicted using HSPiP software. Five distinct cosolvency-based mathematical models were used to link the experimentally determined solubility data of CNZ. The solubility of CNZ in mole fraction was increased with elevated temperature and TP mass fraction in $\{(\mathrm{TP})(1)+$ water $(2)\}$ combinations. The maximum solubility of CNZ in mole fraction was achieved in neat $\mathrm{TP}\left(5.83 \times 10^{-2}\right.$ at $\left.313.2 \mathrm{~K}\right)$ followed by the minimum in neat water $\left(3.91 \times 10^{-8}\right.$ at $\left.293.2 \mathrm{~K}\right)$. The values of mean percent deviation $(M P D)$ were estimated as $2.27 \%, 5.15 \%, 27.76 \%, 1.24 \%$ and $1.52 \%$ for the "Apelblat, van't Hoff, Yalkowsky-Roseman, Jouyban-Acree, and Jouyban-Acree-van't Hoff models", respectively, indicating good correlations. The HSP value of CNZ was closed with that of neat TP, suggesting the maximum solubilization of CNZ in TP compared with neat water and other aqueous mixtures of TP and water. The outcomes of the apparent thermodynamic analysis revealed that CNZ dissolution was endothermic and entropy-driven in all of the $\{(\mathrm{TP})(1)+$ water (2) $\}$ systems investigated. For $\{(\mathrm{TP})(1)+$ water (2) $\}$ mixtures, the enthalpy-driven mechanism was determined to be the driven mechanism for CNZ solvation. TP has great potential for solubilizing the weak base, CNZ, in water, as demonstrated by these results.
\end{abstract}

Keywords: cinnarizine; $\{$ Transcutol-P (1) + water (2)\} mixtures; correlation; solubility; thermodynamics

\section{Introduction}

Cinnarizine (CNZ) (Figure 1, IUPAC name: 1-benzhydryl-4-[(E)-3-phenylprop-2enyl]piperazine, CAS number: 298-57-7, PubChem CID: 1547484, molecular formula: $\mathrm{C}_{26} \mathrm{H}_{28} \mathrm{~N}_{2}$, and molar mass: $368.50 \mathrm{~g} \mathrm{~mol}^{-1}$ ) appears as a white crystalline powder [1,2]. It is used as an antihistaminic and blood-flow promoter [2,3]. The biopharmaceutical classification system (BCS) classifies it as a BCS class II drug, meaning it has poor aqueous solubility and high permeability [1,4]. It is a weak base, which is practically insoluble in water with a high partition coefficient value $(\log P=5.8)$ [5]. Hence, the bioavailability and oral absorption of $\mathrm{CNZ}$ are limited by its low solubility and poor dissolution rate [1]. CNZ is a non-efficient drug molecule due to its low solubility, stability, and poor bioavailability from a physicochemical viewpoint [1-5]. Various lipid-based drug delivery systems, such as self-nanoemulsifying drug delivery systems (SNEDDS) and solidified SNEDDS, have been developed to modify the physicochemical characteristics of CNZ [2,6-14].

Physicochemically, the solubility of active pharmaceutical compounds is an important property for the purification, production, dosage form design, and application of these compounds $[1,15,16]$. The literature on the solubility data of CNZ in aqueous cosolvent 
mixtures is limited. It has $\mathrm{pH}$-dependent solubility in aqueous media [2]. Its solubility increases with decreases in $\mathrm{pH}$, and vice versa. The solubility of $\mathrm{CNZ}$ has been reported as $0.29 \mathrm{mg} \mathrm{mL}^{-1}$ in an aqueous buffer with $\mathrm{pH}=2.0,0.017 \mathrm{mg} \mathrm{mL}^{-1}, \mathrm{pH}=5.0$, and $0.002 \mathrm{mg} \mathrm{mL}^{-1}, \mathrm{pH}=6.5$ at $310.2 \mathrm{~K}$ [2]. The solubility of $\mathrm{CNZ}$ has also been reported in water and four organic solvents such as acetonitrile, butyl acetate, 1-butanol, and 2propanol between 288.15 and $313.15 \mathrm{~K}$ [1].<smiles>C(=C/c1ccccc1)\CN1CCN(C(c2ccccc2)c2ccccc2)CC1</smiles>

Figure 1. Molecular structure of cinnarizine (CNZ).

The solubility values and thermodynamic properties of CNZ (3) are not known in various \{Transcutol-P (TP) (1) + water (2)\} mixtures from 293.2-313.2 K and at 0.1 MPa. Thus, this study evaluated the equilibrium solubility values and thermophysical characteristics of CNZ (3) in various $\{\mathrm{TP}(1)+$ water (2) $\}$ combinations along with pure TP and pure water between 293.2 and $313.2 \mathrm{~K}$ and at $0.1 \mathrm{MPa}$. From a pharmaceutical point of view, TP is a safe and Food and Drug Administration (FDA)-approved solubilizer [2]. It is used as a potential solubilizer/cosolvent in the preparation of various lipid-based drug delivery systems $[2,9,17]$. Recently, it has also been studied as a potential solubilizer in the solubility enhancement of various poorly soluble drugs, including sunitinib malate, flufenamic acid, sinapic acid, apremilast, ketokonazole, and sulphadiazine [18-23]. Due to these reasons, it was selected as a cosolvent in this study.

\section{Results and Discussion}

\subsection{Mole Fraction Solubility Data of CNZ}

Between 293.2 and $313.2 \mathrm{~K}$ and atmospheric pressure, Table 1 lists the solubility values of CNZ in mole fraction (3) in binary $\{\mathrm{TP}(1)+$ water (2)\} combinations, including neat TP and neat water. The solubility of CNZ in mole fraction (3) in different \{TP (1) + water (2)\} combinations at various temperatures is unknown. However, the solubility of CNZ in mole fractions in water has been measured at various temperatures [1]. The mole fraction solubility of CNZ in water was reported to be $6.63 \times 10^{-8}, 7.71 \times 10^{-8}$, and $9.35 \times 10^{-8}$ at $298.3 \mathrm{~K}, 303.0 \mathrm{~K}$, and $307.8 \mathrm{~K}$, respectively [1]. The mole fraction solubility of CNZ in water was determined to be $5.67 \times 10^{-8}, 7.82 \times 10^{-8}$, and $9.78 \times 10^{-8}$ at three closed temperatures of $298.2 \mathrm{~K}, 303.2 \mathrm{~K}$, and $308.2 \mathrm{~K}$, respectively. In neat water, these CNZ mole fraction solubility values were similar to those previously reported in the literature [1]. 
Table 1. Solubility values $\left(x_{\mathrm{e}}\right)$ of cinnarizine (CNZ) in mole fraction (3) in binary \{Transcutol-P (TP) (1) + water (2) $\}$ combinations from $293.2-313.2 \mathrm{~K}$ and at $0.1 \mathrm{MPa}{ }^{\text {a }}$.

\begin{tabular}{|c|c|c|c|c|c|}
\hline \multirow{2}{*}{$w_{1}^{a}$} & \multicolumn{5}{|c|}{$x_{\mathrm{e}^{\mathrm{b}}}^{\mathrm{b}}$} \\
\hline & $T=293.2 \mathrm{~K}$ & $T=298.2 \mathrm{~K}$ & $T=303.2 \mathrm{~K}$ & $T=308.2 \mathrm{~K}$ & $T=313.2 \mathrm{~K}$ \\
\hline 0.0 & $3.91 \times 10^{-8}$ & $5.67 \times 10^{-8}$ & $7.82 \times 10^{-8}$ & $9.78 \times 10^{-8}$ & $1.42 \times 10^{-7}$ \\
\hline 0.1 & $1.66 \times 10^{-7}$ & $2.30 \times 10^{-7}$ & $3.16 \times 10^{-7}$ & $3.91 \times 10^{-7}$ & $5.30 \times 10^{-7}$ \\
\hline 0.2 & $6.50 \times 10^{-7}$ & $8.87 \times 10^{-7}$ & $1.23 \times 10^{-6}$ & $1.51 \times 10^{-6}$ & $1.95 \times 10^{-6}$ \\
\hline 0.3 & $2.64 \times 10^{-6}$ & $3.50 \times 10^{-6}$ & $4.49 \times 10^{-6}$ & $5.35 \times 10^{-6}$ & $7.00 \times 10^{-6}$ \\
\hline 0.4 & $1.12 \times 10^{-5}$ & $1.42 \times 10^{-5}$ & $1.72 \times 10^{-5}$ & $2.09 \times 10^{-5}$ & $2.62 \times 10^{-5}$ \\
\hline 0.5 & $4.24 \times 10^{-5}$ & $5.26 \times 10^{-5}$ & $6.34 \times 10^{-5}$ & $7.33 \times 10^{-5}$ & $9.22 \times 10^{-5}$ \\
\hline 0.6 & $1.73 \times 10^{-4}$ & $2.10 \times 10^{-4}$ & $2.44 \times 10^{-4}$ & $2.77 \times 10^{-4}$ & $3.36 \times 10^{-4}$ \\
\hline 0.7 & $6.89 \times 10^{-4}$ & $8.00 \times 10^{-4}$ & $9.22 \times 10^{-4}$ & $1.05 \times 10^{-3}$ & $1.23 \times 10^{-3}$ \\
\hline 0.8 & $2.81 \times 10^{-3}$ & $3.17 \times 10^{-3}$ & $3.53 \times 10^{-3}$ & $3.90 \times 10^{-3}$ & $4.43 \times 10^{-3}$ \\
\hline 0.9 & $1.12 \times 10^{-2}$ & $1.25 \times 10^{-2}$ & $1.38 \times 10^{-2}$ & $1.48 \times 10^{-2}$ & $1.62 \times 10^{-2}$ \\
\hline 1.0 & $4.52 \times 10^{-2}$ & $4.78 \times 10^{-2}$ & $5.08 \times 10^{-2}$ & $5.44 \times 10^{-2}$ & $5.83 \times 10^{-2}$ \\
\hline
\end{tabular}

a The uncertainties $u$ are $u(T)=0.2 \mathrm{~K}, u\left(w_{1}\right)=0.0007$, and $u(p)=2 \mathrm{kPa}$. ${ }^{\mathrm{b}}$ The relative uncertainty $u_{\mathrm{r}}$ in solubility is $u_{\mathrm{r}}\left(x_{\mathrm{e}}\right)=0.016$.

The mole fraction solubility of CNZ was determined to be the lowest in neat water and the highest in neat TP. The low polarity of TP relative to the high polarity of water may explain the maximal CNZ solubility in neat TP $[18,19]$. The solubility of CNZ (3) in binary $\{\mathrm{TP}(1)+$ water (2)\} combinations was observed to increase with elevated temperatures and increase in TP mass fraction at constant pressure (0.1 MPa) between 293.2 and $313.2 \mathrm{~K}$. Between 293.2 and $313.2 \mathrm{~K}$, the effect of TP mass fraction on the logarithmic mole fraction solubility of CNZ was also investigated, and the findings are shown in Figure 2. At all five temperatures tested, the logarithmic solubility of CNZ in mole fraction was enhanced consistently with an increase in TP mass fraction in binary $\{$ TP (1) + water (2)\} combinations. The logarithmic solubility of CNZ in mole fraction was likewise shown to enhance significantly from pure water to pure TP. As a result, TP has the potential to be employed as a solubilizer/cosolvent in the solubilization of CNZ in water.

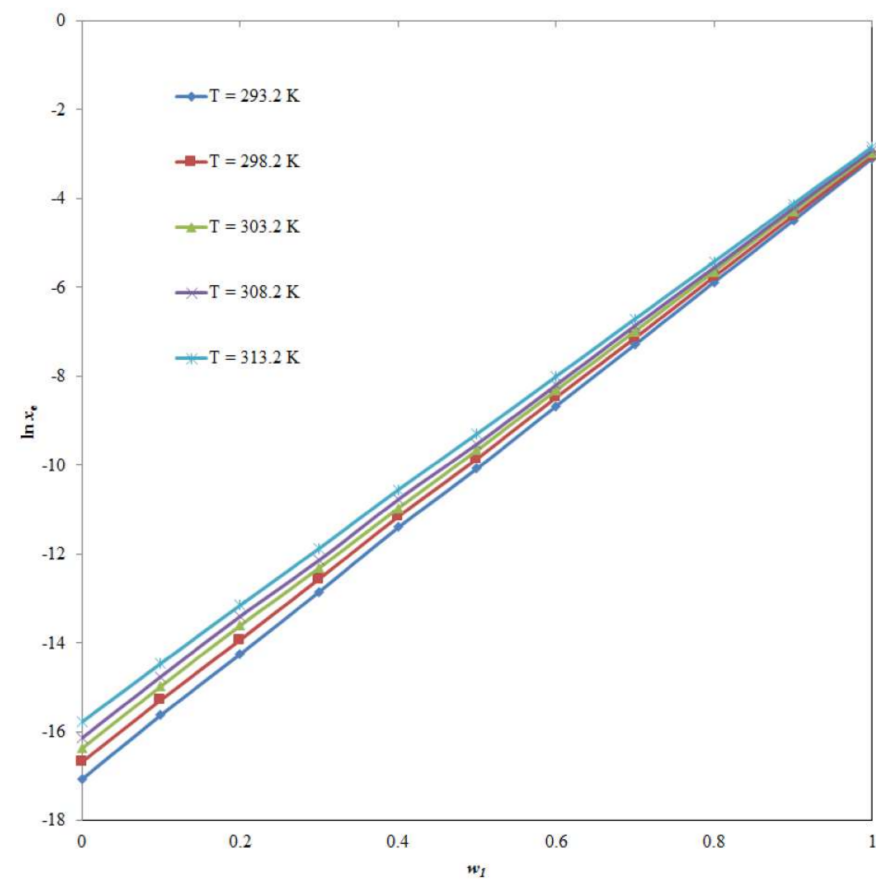

Figure 2. Influence of Transcutol-P (TP) mass fraction $\left(w_{1}\right)$ on logarithmic solubilities of CNZ between 293.2 and $313.2 \mathrm{~K}$. 


\subsection{Hansen Solubility Parameters (HSPs)}

The total HSP $\left(\delta_{\mathrm{t}}\right)$ for $\mathrm{CNZ}$ was estimated to be $19.40 \mathrm{MPa}^{1 / 2}$ using HSPiP software and Equation (1). HSP values for neat TP $\left(\delta_{1}\right)$ and neat water $\left(\delta_{2}\right)$ were anticipated to be 21.40 and $47.80 \mathrm{MPa}^{1 / 2}$, respectively. Equation (2) was used to calculate the HSP value for various $\{\mathrm{TP}(1)+$ water $(2)\}$ combinations free of $\mathrm{CNZ}\left(\delta_{\text {mix }}\right)$. The $\delta_{\text {mix }}$ values were estimated to be between 24.04 and $45.16 \mathrm{MPa}^{1 / 2}$. Overall, the HSP of neat TP $\left(\delta_{1}=21.40 \mathrm{MPa}^{1 / 2}\right)$ and CNZ $\left(\delta_{t}=19.40 \mathrm{MPa}^{1 / 2}\right)$ were very close. The solubility of CNZ in neat TP was likewise found to be the highest in the experiments. As a result, these findings were in good accord with the CNZ solubility data obtained from experiments with \{TP (1) + water (2)\} combinations.

\subsection{Cosolvency-Based Mathematical Models for CNZ Solubility Correlation}

Five distinct cosolvency-based mathematical models, including the modified "Apelblat, van't Hoff, Yalkowsky-Roseman, Jouyban-Acree, and Jouyban-Acree-van't Hoff models" were used to link the measured solubility values of CNZ [18-20,24-27]. Table 2 summarizes the results for the correlation of CNZ in binary $\{\mathrm{TP}(1)+$ water (2)\} combinations with the modified "Apelblat model". The overall mean percent deviation $(M P D)$ for this model was estimated to be $2.27 \%$. The determination coefficient $\left(R^{2}\right)$ for CNZ (3) in all cosolvent combinations with neat solvents was obtained at between 0.9955 and 0.9998 . These findings revealed a strong connection between the experimental CNZ (3) solubility data and the modified "Apelblat model" in binary $\{$ TP (1) + water (2)\} combinations.

Table 2. Results for the modified "Apelblat model" for CNZ (3) in various $\{\mathrm{TP}(1)+$ water (2)\} combinations.

\begin{tabular}{cccccc}
\hline $\mathbf{w}_{\mathbf{1}}$ & $\mathbf{A}$ & $\mathbf{B}$ & $\mathbf{C}$ & $\boldsymbol{R}^{\mathbf{2}}$ & $\mathbf{M P D} \mathbf{( \% )}$ \\
\hline 0.0 & 224.09 & -15741 & -32.997 & 0.9956 & - \\
0.1 & 286.07 & -18057 & -42.264 & 0.9979 & - \\
0.2 & 442.94 & -24887 & -65.536 & 0.9980 & - \\
0.3 & 211.39 & -13815 & -31.176 & 0.9969 & - \\
0.4 & -25.275 & -2611.0 & 4.0112 & 0.9988 & - \\
0.5 & 8.3136 & -3761.7 & -0.97648 & 0.9957 & 2.27 \\
0.6 & 53.365 & -5294.9 & -7.7389 & 0.9956 & - \\
0.7 & -72.315 & 715.43 & 11.018 & 0.9955 & - \\
0.8 & -46.705 & 101.83 & 7.1263 & 0.9981 & - \\
0.9 & 127.04 & -7373.2 & -18.728 & 0.9994 & - \\
1.0 & -132.56 & 4855.2 & 19.875 & 0.9998 & - \\
\hline
\end{tabular}

Table 3 summarizes the results for the correlation of CNZ in binary \{TP (1) + water (2)\} combinations with the "van't Hoff model". The overall MPD for the "van't Hoff model" was estimated to be $5.15 \%$. The $R^{2}$ for CNZ (3) in all cosolvent mixtures with neat solvents was obtained at between 0.9947 and 0.9993 . These findings also revealed a strong connection between experimental CNZ (3) solubility data and the "van't Hoff model" in binary $\{$ TP (1) + water (2)\} combinations.

Table 4 summarizes the results for the correlation of CNZ in binary \{TP (1) + water (2)\} combinations with the "Yalkowsky-Roseman model". The MPD for this model was estimated to be $24.76 \%$, also showing a strong connection between experimental CNZ (3) solubility data and the "Yalkowsky-Roseman model" in binary \{TP (1) + water (2)\} combinations. 
Table 3. Resulting data for "van't Hoff model" for CNZ (3) in different $\{$ TP (1) + water (2)\} combinations.

\begin{tabular}{ccccc}
\hline $\mathbf{w}_{\mathbf{1}}$ & $\mathbf{a}$ & $\mathbf{b}$ & $\boldsymbol{R}^{\mathbf{2}}$ & $\mathbf{M P D}(\mathbf{\%})$ \\
\hline 0.0 & 2.5154 & -5733.0 & 0.9947 & \\
0.1 & 2.2793 & -5240.5 & 0.9967 & \\
0.2 & 2.8838 & -5015.9 & 0.9953 & \\
0.3 & 2.0440 & -4360.6 & 0.9959 & 5.15 \\
0.4 & 1.6487 & -3824.2 & 0.9987 & 0.9954 \\
0.5 & 1.7473 & -3462.8 & 0.9952 & 0.9993 \\
0.6 & 1.3939 & -2946.3 & 0.9978 & 0.9973 \\
0.7 & 1.6646 & -2623.1 & 0.9960 \\
0.8 & 1.1397 & -2057.0 & -1694.4 & \\
\hline
\end{tabular}

Table 4. Resulting data for "Yalkowsky-Roseman model" for CNZ (3) in different \{TP (1) + water (2)\} combinations from $293.2-313.2 \mathrm{~K}$.

\begin{tabular}{|c|c|c|c|c|c|c|}
\hline \multirow{2}{*}{$w_{1}$} & \multicolumn{5}{|c|}{$\log x^{\text {Yal }}$} & \multirow{2}{*}{$\frac{\text { MPD (\%) }}{-}$} \\
\hline & $T=293.2 \mathrm{~K}$ & $T=298.2 \mathrm{~K}$ & $T=303.2 \mathrm{~K}$ & $T=308.2 \mathrm{~K}$ & $T=313.2 \mathrm{~K}$ & \\
\hline 0.1 & -6.80 & -6.65 & -6.52 & -6.43 & -6.28 & - \\
\hline 0.2 & -6.19 & -6.06 & -5.94 & -5.86 & -5.72 & - \\
\hline 0.3 & -5.58 & -5.46 & -5.36 & -5.28 & -5.16 & - \\
\hline 0.4 & -4.98 & -4.87 & -4.78 & -4.71 & -4.60 & 24.76 \\
\hline 0.5 & -4.37 & -4.28 & -4.20 & -4.13 & -4.04 & - \\
\hline 0.6 & -3.77 & -3.69 & -3.61 & -3.56 & -3.47 & - \\
\hline 0.7 & -3.16 & -3.09 & -3.03 & -2.98 & -2.91 & - \\
\hline 0.8 & -2.55 & -2.50 & -2.45 & -2.41 & -2.35 & - \\
\hline 0.9 & -1.95 & -1.91 & -1.87 & -1.83 & -1.79 & - \\
\hline
\end{tabular}

The solubility values of CNZ (3) in \{TP (1) + water (2)\} compositions at various temperatures and cosolvent compositions can also be correlated using the "Jouyban-Acree and Jouyban-Acree-van't Hoff models" [28]. The overall MPDs were determined as $1.24 \%$ and $1.52 \%$ for "Jouyban-Acree and Jouyban-Acree-van't Hoff models", respectively. The overall MPD for the "Yalkowsky-Roseman model" was the highest compared with the other models studied. In the "Yalkowsky-Roseman model", the model parameters were not utilized (equal to zero) compared to the other models studied. Therefore, the highest $M P D$ value for the "Yalkowsky-Roseman model" was due to the fact that this model did not utilize any model parameters for the calculation of MPD $[19,26]$.

\subsection{Apparent Thermodynamic Parameters for CNZ}

The apparent standard enthalpy $\left(\Delta_{\text {soln }} H^{\circ}\right)$ values for CNZ (3) in all cosolvent mixtures, including neat solvents, were calculated using the van't Hoff technique. As reported in Table 5, Figure 3 displays the linear van't Hoff curves of CNZ (3) in all cosolvent compositions and pure solvents where $\mathrm{R}^{2}$ was more than 0.990 . Table 5 also includes the values of all thermodynamic quantities. The CNZ (3) $\Delta_{\text {soln }} H^{\circ}$ values in binary $\{\mathrm{TP}$ (1) + water (2)\} combinations with pure solvents ranged from 9.719 to $47.65 \mathrm{~kJ} \mathrm{~mol}^{-1}$. In various $\{\mathrm{TP}(1)+$ water (2)\} mixtures including neat solvents, the apparent standard Gibbs energy $\left(\Delta_{\text {soln }} G^{\circ}\right)$ values for CNZ (3) were computed between 7.492 and $41.32 \mathrm{~kJ} \mathrm{~mol}^{-1}$. The endothermic dissolution of CNZ (3) in various $\{\mathrm{TP}(1)+$ water (2) $\}$ combinations with pure solvents was demonstrated by the obtained values of $\Delta_{\text {soln }} H^{\circ}$ for CNZ $[18,19]$. The $\Delta_{\text {soln }} H^{\circ}$ and $\Delta_{\text {soln }} G^{\circ}$ values are inversely proportional to the solubility of the solute. Hence, the maximum $\Delta_{\text {soln }} H^{\circ}$ and $\Delta_{\text {soln }} G^{\circ}$ values for CNZ were obtained in neat water compared to the neat TP. The apparent standard entropy $\left(\Delta_{\text {soln }} S^{\circ}\right)$ values for CNZ (3) in binary \{TP (1) + water (2)\} combinations with neat solvents were computed between 7.346 and $23.94 \mathrm{~J}$ $\mathrm{mol}^{-1} \mathrm{~K}^{-1}$, implying the entropy-driven dissolution of CNZ (3) in diverse \{TP (1) + water 
(2)\} combinations with pure solvents [18]. Finally, in all \{TP (1) + water (2)\} combinations, including pure solvents, the dissolution of CNZ (3) was reported to be endothermic and entropy-driven $[18,19]$.

Table 5. Apparent standard enthalpy $\left(\Delta_{\text {soln }} H^{\circ}\right)$, apparent standard Gibbs energy $\left(\Delta_{\text {soln }} G^{\circ}\right)$, apparent standard entropy $\left(\Delta_{\text {soln }} S^{\circ}\right)$, and van't Hoff $R^{2}$ values for CNZ (3) in different \{TP (1) + water (2)\} combinations at $T_{\mathrm{hm}}=303.0 \mathrm{~K}^{\mathrm{a}}$.

\begin{tabular}{ccccc}
\hline $\mathbf{w}_{\mathbf{1}}$ & $\begin{array}{c}\boldsymbol{\Delta}_{\text {soln }} \mathbf{H}^{\circ} \mathbf{/ k J} \\
\mathbf{m o l}\end{array}$ & $\begin{array}{c}\boldsymbol{\Delta}_{\text {soln }} \mathbf{1} G^{\circ} / \mathbf{k J} \\
\mathbf{m o l}^{-\mathbf{1}}\end{array}$ & $\begin{array}{c}\boldsymbol{\Delta}_{\text {soln }} \boldsymbol{S}^{\circ} / \mathbf{J} \mathbf{~ m o l}^{-\mathbf{1}} \\
\mathbf{K}^{-\mathbf{1}}\end{array}$ & $\boldsymbol{R}^{\mathbf{2}}$ \\
\hline 0.0 & 47.65 & 41.32 & 20.48 & 0.994 \\
0.1 & 43.56 & 37.82 & 18.92 & 0.996 \\
0.2 & 41.69 & 34.43 & 23.94 & 0.995 \\
0.3 & 36.24 & 31.10 & 16.96 & 0.995 \\
0.4 & 31.78 & 27.64 & 13.68 & 0.998 \\
0.5 & 28.78 & 24.38 & 14.50 & 0.995 \\
0.6 & 24.49 & 20.98 & 11.57 & 0.995 \\
0.7 & 21.80 & 17.61 & 13.82 & 0.999 \\
0.8 & 17.09 & 14.23 & 9.464 & 0.997 \\
0.9 & 14.08 & 10.83 & 10.72 & 0.997 \\
1.0 & 9.719 & 7.492 & 7.346 & 0.996 \\
\hline
\end{tabular}

a The relative uncertainties are $u_{\mathrm{r}}\left(\Delta_{\text {soln }} H^{0}\right)=0.043, u_{\mathrm{r}}\left(\Delta_{\text {soln }} G^{0}\right)=0.045$, and $u_{\mathrm{r}}\left(\Delta_{\text {soln }} S^{0}\right)=0.034$.

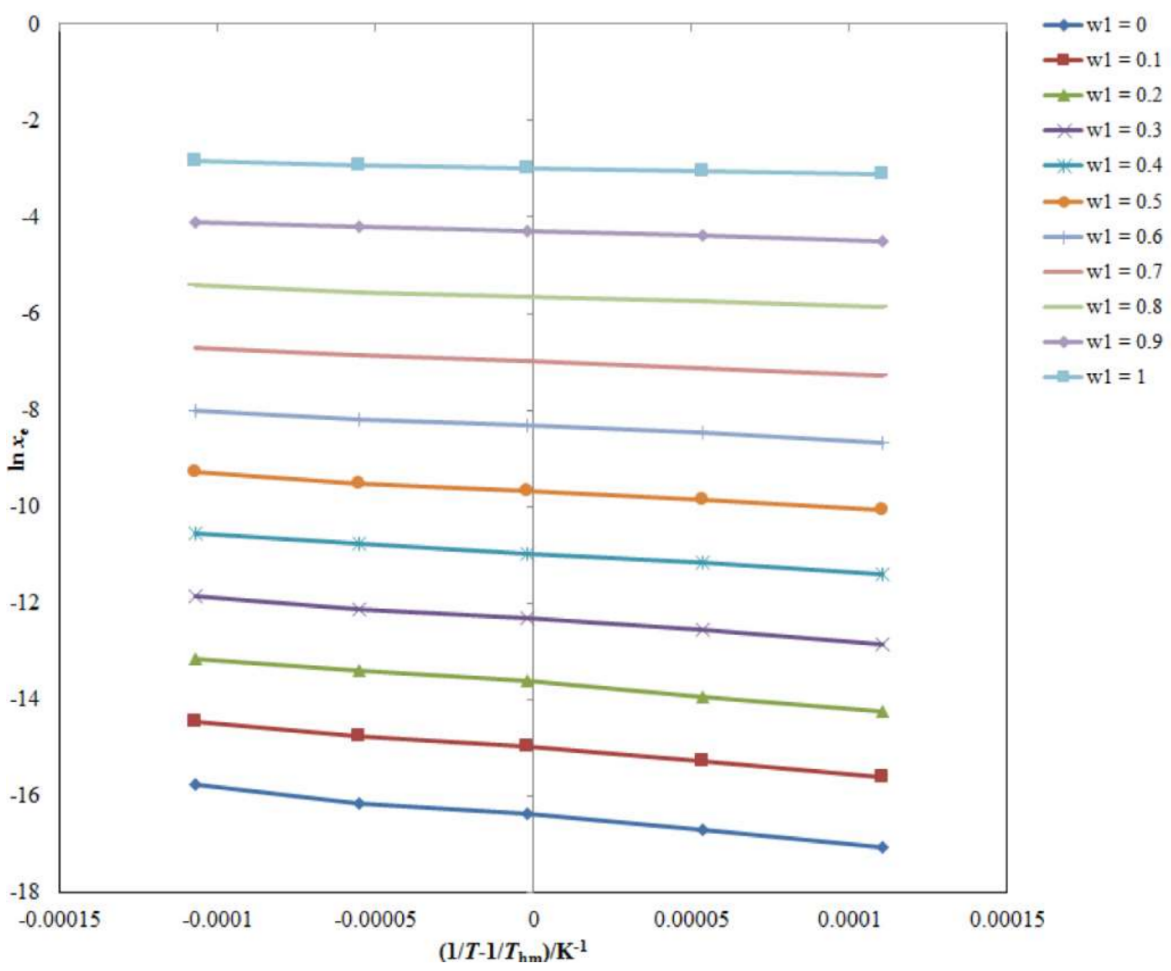

Figure 3. Van't Hoff curves for logarithmic solubility of CNZ (3) in aqueous mixtures of TP (1) and water (2).

\subsection{Enthalpy-Entropy Compensation Analysis}

An enthalpy-entropy compensation study was used to analyze the solvation behavior/cosolvent action of CNZ (3) in binary $\{\mathrm{TP}(1)+$ water (2) $\}$ combinations with pure solvents, and the findings are shown in Figure 4. Figure 4 shows that CNZ (3) offers a linear $\Delta_{\text {soln }} H^{\circ}$ vs. $\Delta_{\text {soln }} G^{\circ}$ trend in all $\{\mathrm{TP}(1)+$ water (2)\} combinations with pure solvents, with a slope value of 1.124 and $R^{2}=0.997$. Based on these findings, the driving mechanism for CNZ (3) solvation in all \{TP (1) + water (2)\} combinations, including neat solvents, is 
assumed to be enthalpy-driven. This method of CNZ solvation could be explained by the fact that CNZ solvates best in neat TP molecules compared to neat water molecules $[19,28]$. As a result, the molecular interactions between CNZ-TP molecules were stronger than those between CNZ-water molecules. This solvation behavior of CNZ (3) in binary \{TP (1) + water (2)\} combinations with pure solvents was identical to that of flufenamic acid, piperine, sinapic acid, sunitinib malate, apigenin, and apremilast in binary \{TP (1) + water (2)\} combinations [18-20,29-31].

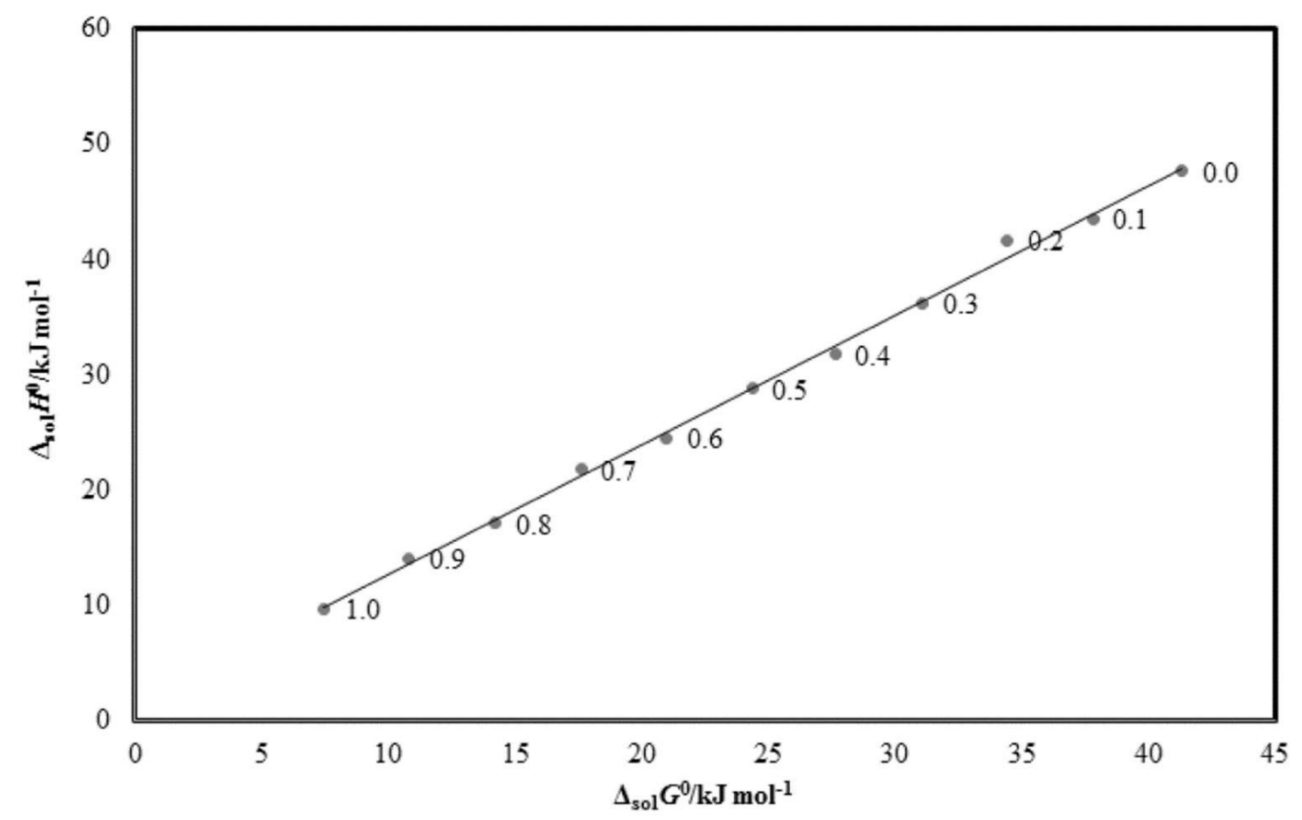

Figure 4. $\Delta_{\text {sol }} H^{\circ}$ vs. $\Delta_{\text {sol }} G^{\circ}$ enthalpy-entropy compensation plot for solubility of CNZ in various $\{\mathrm{TP}(1)+$ water (2) $\}$ mixtures at $T_{\mathrm{hm}}=303.0 \mathrm{~K}$.

\section{Materials and Methods}

\subsection{Materials}

CNZ (mass fraction purity $>0.99$ by HPLC) was procured from FDC Ltd. (Mumbai, India). TP (mass fraction purity $>0.99$ by GC) was obtained from Gattefosse (Lyon, France) The water utilized in this research was deionized and came from the laboratory's Milli-Q unit. Table 6 summarizes the materials information.

Table 6. Materials list.

\begin{tabular}{cccccccc}
\hline Material & $\begin{array}{c}\text { Molecular } \\
\text { Formula }\end{array}$ & $\begin{array}{c}\text { Molar Mass } \\
\left(\mathbf{g ~ m o l}^{-1}\right)\end{array}$ & CAS RN & $\begin{array}{c}\text { Purification } \\
\text { Method }\end{array}$ & $\begin{array}{c}\text { Mass } \\
\text { Fraction } \\
\text { Purity }\end{array}$ & $\begin{array}{c}\text { Analysis } \\
\text { Method }\end{array}$ \\
\hline $\mathrm{CNZ}$ & $\mathrm{C}_{26} \mathrm{H}_{28} \mathrm{~N}_{2}$ & 368.50 & $298-57-7$ & None & $>0.99$ & HPLC \\
$\mathrm{TP}$ & $\mathrm{C}_{6} \mathrm{H}_{14} \mathrm{O}_{3}$ & 134.17 & $111-90-0$ & None & $>0.99$ & FDC Ltd. \\
Water & $\mathrm{H}_{2} \mathrm{O}$ & 18.07 & $7732-18-5$ & None & - & Gattefosse \\
Milli-Q & - & \\
\hline
\end{tabular}

CNZ: cinnarizine; TP: Transcutol-P; HPLC: high-performance liquid chromatography; GC: gas chromatography.

\subsection{CNZ (3) Solubility Determination in Binary $\{T P(1)+$ Water (2)\} Combinations}

Using a Digital Analytical Balance (Mettler Toledo, Greifensee, Switzerland) with a sensitivity of $0.10 \mathrm{mg}$, all $\{\mathrm{TP}(1)+$ water (2) $\}$ combinations were created on a mass basis. The mass fraction of TP used to make various $\{$ TP (1) + water (2)\} compositions ranged from $0.10-0.90$. Three replicates of each $\{\mathrm{TP}(1)+$ water $(2)\}$ composition were made.

Using a standard shake-flask method [32], the mole fraction solubility of CNZ against the mass fraction of TP $\left(w_{1}=0.0-1.0 ; w_{1}\right.$ is TP mass fraction in $\{\mathrm{TP}(1)+$ water (2) $\}$ com- 
positions) and pure solvents was tested from $293.2-313.2 \mathrm{~K}$ and at $0.1 \mathrm{MPa}$ in various (TP (1) + water (2)\} mixtures and pure solvents. Extra CNZ crystals were mixed with known amounts of each $\{$ TP (1) + water (2) \} composition and neat solvents. Three repetitions of each experiment were carried out. Inside the Biological Shaker (Julabo, PA, USA), the acquired samples were saturated for three days to achieve equilibrium. After reaching equilibrium, the saturated samples were withdrawn from the shaker and centrifuged at $5000 \mathrm{rpm}$. The supernatants were withdrawn, diluted (wherever applicable), and used for the estimation of CNZ content using a reported HPLC method at $253 \mathrm{~nm}$ [12]. The mole fraction solubilities $\left(x_{\mathrm{e}}\right)$ of $\mathrm{CNZ}$ were calculated using their standard formulae [20,33].

\subsection{HSPs of CNZ and Various $\{T P(1)+$ Water (2) $\}$ Mixtures}

The HSP of a pharmaceutical compound is associated with its solubility in neat solvent or aqueous-cosolventmixtures. It is well-known that the closed value of the HSP of a pharmaceutical compound with that of a particular solvent could result in the maximum solubility of a pharmaceutical compound in that particular solvent [34]. Hence, the HSP for CNZ, neat TP, and neat water were predicted in this research. The $\delta_{\mathrm{t}}$ value for CNZ, neat TP, and neat water was predicted using Equation (1) [35-38]:

$$
\delta_{\mathrm{t}}^{2}=\delta_{\mathrm{d}}^{2}+\delta_{\mathrm{p}}^{2}+\delta_{\mathrm{h}}^{2}
$$

where $\delta_{\mathrm{d}}=$ dispersion HSP; $\delta_{\mathrm{p}}=$ polar HSP, and $\delta_{\mathrm{h}}=$ hydrogen-bonded HSP. These values for CNZ and neat solvents were predicted utilizing HSPiP software (version 4.1.07, Louisville, KY, USA) by entering the simplified molecular input line entry system (SMILES) of each component into the HSPiP system [36].

The HSP for various $\{$ TP $(1)+$ water $(2)\}$ mixture free of $\mathrm{CNZ}\left(\delta_{\text {mix }}\right)$ was calculated using Equation (2) [38]:

$$
\delta_{\text {mix }}=\propto \delta_{1}+(1-\propto) \delta_{2}
$$

where, $\alpha=$ volume fraction of TP in $\{\mathrm{TP}(1)+$ water (2) $\}$ mixture; $\delta_{1}=$ HSP of neat TP, and $\delta_{2}=$ HSP of neat water.

\subsection{Cosolvency-Based Mathematical Models for CNZ Solubility Correlation}

The mathematical correlation of experimental data of pharmaceutical compounds is important for practical predictions/validations [20,33,39,40]. As a result, the measured solubility values of CNZ were predicted using the modified "Apelblat, van't Hoff, YalkowskyRoseman, Jouyban-Acree, and Jouyban-Acree-van't Hoff models" [18-20,24-27].

The "Apelblat model solubility $\left(x^{\mathrm{Apl}}\right)$ " of CNZ (3) in binary $\{\mathrm{TP}(1)+$ water (2) combinations was predicted using Equation (3) [24,25]:

$$
\ln x^{\mathrm{Apl}}=A+\frac{B}{T}+C \ln (T)
$$

where $A, B$, and $C$ are the model parameters of Equation (3), which were determined using nonlinear multivariate regression analysis of experimental solubility data of CNZ summarized in Table 1 [18]. The correlation between $x_{\mathrm{e}}$ and $x^{\mathrm{Apl}}$ of CNZ was performed using $M P D$. The $M P D$ was calculated using its reported formula [27].

The "van't Hoff model solubility ( $\left.x^{\text {van't }}\right)$ " of CNZ (3) in binary \{TP (1) + water (2)\} combinations is predicted using Equation (4) [20]:

$$
\ln x^{\operatorname{van}^{\prime} \mathrm{t}}=a+\frac{b}{T}
$$

where $a$ and $b$ are the Equation (4) parameters, which were found using the least square technique [19]. The solubility values in a specific solvent combination at different temperatures are represented by Equations (3) and (4), and there is no way to forecast the solubility values in other solvent mixtures of binary solvent composition. 
The logarithmic solubility of the "Yalkowsky-Roseman model (log $\left.x^{\text {Yal }}\right)$ " for CNZ (3) in various $\{$ TP (1) + water (2) $\}$ combinations was predicted by Equation (5) [26]:

$$
\log x^{\mathrm{Yal}}=w_{1} \log x_{1}+w_{2} \log x_{2}
$$

where $x_{1}=$ the solubility of CNZ (3) in TP (1); $x_{2}=$ the solubility of CNZ in water (2); $w_{1}=$ TP mass fraction, and $w_{2}=$ water mass fraction. Equation (5) models the solubility values of pharmaceutical compounds in different solvent mixtures at a given temperature.

The "Jouyban-Acree model" correlates the solubility of pharmaceutical compounds at the solvent compositions as well as temperature $\left(x_{\mathrm{m}, \mathrm{T}}\right)$, and was predicted using Equation (6) [27]:

$$
\ln x_{m, T}=w_{1} \ln x_{1, T}+w_{2} \ln x_{2, T}+\left(\frac{w_{1} \cdot w_{2}}{T}\right) \sum_{i=0}^{2} J_{i}\left(w_{1}-w_{2}\right)^{i}
$$

where $x_{1, \mathrm{~T}}$ and $x_{2, \mathrm{~T}}$ are the solubility of CNZ in TP (1) and water (2) at temperature $T$, and the symbols $J$ are the model parameters. The solubility values of CNZ in pure solvents are required as input data to predict the solubility of CNZ in cosolvent compositions at the temperature of interest. To overcome this constraint, Equations (2) and (6) can be combined to form the "Jouyban-Acree-van't Hoff model" [27].

\subsection{Apparent Thermodynamic Parameters for CNZ}

At the mean harmonic temperature $\left(T_{\mathrm{hm}}\right)$, all apparent thermodynamic parameters were examined. The $T_{\mathrm{hm}}$ was calculated using the usual formula [27]. In this study, the $T_{\mathrm{hm}}$ was found to be $303.0 \mathrm{~K}$. An apparent thermodynamic analysis was used to calculate several apparent thermodynamic parameters. The van't Hoff and Gibbs equations were used to conduct this analysis. Equation (7) was used to determine the $\Delta_{\text {soln }} H^{\circ}$ values for CNZ (3) in binary $\{\mathrm{TP}(1)+$ water (2) $\}$ combinations at $T_{\mathrm{hm}}=303.0 \mathrm{~K}$ using the van't Hoff methodology $[28,41]$ :

$$
\left(\frac{\partial \ln x_{e}}{\partial\left(\frac{1}{T}-\frac{1}{T_{\mathrm{hm}}}\right)}\right)_{P}=-\frac{\Delta_{\mathrm{soln}} H^{\circ}}{R}
$$

By plotting $\ln x_{\mathrm{e}}$ values of CNZ vs. $\left(1 / T-1 / T_{\mathrm{hm}}\right)$, the $\Delta_{\text {soln }} H^{\circ}$ and $\Delta_{\text {soln }} G^{\circ}$ values for $\mathrm{CNZ}$ were calculated from the slope and intercept, using the following Equations (8) and (9), respectively $[28,41]$ :

$$
\begin{gathered}
\Delta_{\text {soln }} H^{\circ}=-R\left(\frac{\partial \ln x_{e}}{\partial\left(\frac{1}{T}-\frac{1}{T_{\mathrm{hm}}}\right)}\right)_{P} \\
\Delta_{\text {soln }} G^{\circ}=-R T_{\mathrm{hm}} \cdot \text { intercept }
\end{gathered}
$$

Equation (10) was used to calculate the $\Delta_{\text {soln }} S^{\circ}$ values for CNZ (3) in binary \{TP (1) + water (2)\} combinations [28,41,42]:

$$
\Delta_{\text {soln }} S^{\circ}=\frac{\Delta_{\text {soln }} H^{\circ}-\Delta_{\text {soln }} G^{\circ}}{T_{\mathrm{hm}}}
$$

\subsection{Enthalpy-Entropy Compensation Analysis}

An enthalpy-entropy compensation analysis was used to analyze the solvation behavior of CNZ (3) in binary \{TP (1) + water (2)\} combinations, as previously proposed [16] This analysis was carried out by plotting the weighted graphs of $\Delta_{\text {soln }} H^{\circ}$ vs. $\Delta_{\text {soln }} G^{\circ}$ at $T_{\mathrm{hm}}=303.0 \mathrm{~K}[17,26]$.

\section{Conclusions}

In the literature, there is scarce data concerning the solubility of $\mathrm{CNZ}$ in diverse aqueous cosolvent mixtures. As a result, the mole fraction solubility data of a weak 
base, CNZ, (3) in binary \{TP (1) + water (2) \} combinations including pure solvents was determined in this investigation from $293.2-313.2 \mathrm{~K}$ and at $0.1 \mathrm{MPa}$. In all $\{\mathrm{TP}(1)+$ water (2)\} compositions, including pure solvents, the mole fraction solubilities of CNZ (3) increased with the rise in temperature and TP mass fraction. At each temperature tested, the maximum and minimum mole fraction solubility of $\mathrm{CNZ}$ were found in neat TP and neat water, respectively. In all \{TP (1) + water (2) combinations including pure solvents, experimentally determined CNZ (3) solubility data correlated well with the "Apelblat, van't Hoff, Yalkowsky-Roseman, Jouyban-Acree, and Jouyban-Acree-van't Hoff models". In all \{TP (1) + water (2)\} combinations, including pure solvents, the dissolution behavior of CNZ was endothermic and entropy-driven. In all $\{\mathrm{TP}(1)+$ water (2)\} combinations, including pure solvents, the predominant mechanism for $\mathrm{CNZ}$ solvation capacity was enthalpy-driven.

Author Contributions: Conceptualization, F.S. and M.K.; methodology, P.A. and F.K.A.; software, P.A.; validation, M.K. and F.K.A.; formal analysis, M.K.; investigation, F.S.; resources, M.K.; data curation, P.A.; writing — original draft preparation, F.S.; writing—review and editing, M.K.; visualization, M.K.; supervision, F.S.; project administration, F.S.; funding acquisition, M.K. All authors have read and agreed to the published version of the manuscript.

Funding: This research was funded by the National Plan for Science, Technology, and Innovation (MAARIFAH), King Abdulaziz City for Science and Technology, Saudi Arabia, Award Number (13NAN929-02) and the APC was funded by MAARIFAH.

Institutional Review Board Statement: Not applicable.

Informed Consent Statement: Not applicable.

Data Availability Statement: This study did not report any data.

Acknowledgments: Authors are thankful to the National Plan for Science, Technology, and Innovation (MAARIFAH), King Abdulaziz City for Science and Technology, Saudi Arabia, Award Number (13NAN929-02) for supporting this work.

Conflicts of Interest: The authors declare no conflict of interest.

Sample Availability: Samples of the compounds CNZ are available from the authors.

\section{References}

1. Paus, R.; Hart, E.; Ji, Y.; Sadowski, G. Solubility and caloric properties of cinnarizine. J. Chem. Eng. Data 2015, 60, 2256-2261. [CrossRef]

2. Raghuvanshi, S.; Pathak, K. Recent advances in drug delivery systems and therapeutics of cinnarizine: A poorly water soluble drug with absorption window in stomach. J. Drug Deliv. 2014, 2014, 479246. [CrossRef] [PubMed]

3. Shi, S.; Chen, H.; Lin, X.; Tang, X. Pharmacokinetics, tissue distribution and safety of cinnarizine delivered in lipid emulsion. Int. J. Pharm. 2010, 383, 264-270. [CrossRef]

4. Amidon, G.L.; Lennernas, H.; Shah, V.P.; Crison, J.R. A theoretical basis for a biopharmaceutic drug classification-the correlation of in-vitro drug product dissolution and in-vivo bioavailability. Pharm. Res. 1995, 12, 413-420. [CrossRef]

5. Loftsson, T.; Hreinsdóttir, D.; Másson, M. Evaluation of cyclodextrin solubilization of drugs. Int. J. Pharm. 2005, 302, 18-28. [CrossRef] [PubMed]

6. Sassene, P.J.; Knopp, M.M.; Hesselkilde, J.Z.; Koradia, V.; Larsen, A.; Rades, T.; Mullertz, A. Precipitation of a poorly soluble model drug during in vitro lipolysis: Characterization and dissolution of the precipitate. J. Pharm. Sci. 2010, 99, $4982-4991$. [CrossRef] [PubMed]

7. Larsen, A.T.; Ogbonna, A.; Abu-Rmaileh, R.; Abrahamsson, B.; Østergaard, J.; Mullertz, A. SNEDDS containing poorly water soluble cinnarizine; development and in vitro characterization of dispersion, digestion and solubilization. Pharmaceutics 2012, 4, 641-655. [CrossRef]

8. Shahba, A.A.-W.; Mohsin, K.; Alanazi, F.K. Novel self-nanoemulsifying drug delivery system (SNEDDS) for oral delivery cinnarizine: Design, optimization, and in-vitro assessment. AAPS PharmSciTech. 2012, 13, 967-977. [CrossRef] [PubMed]

9. Rai, S.; Yasir, M. Cinnarizine-loaded lipid based system: Preparation, optimization, and in-vitro evaluation. IOSR J. Pharm. 2012, 2, 47-56. [CrossRef]

10. Larsen, A.T.; Ohlsson, A.G.; Polentarutti, B.; Barker, R.A.; Phillips, A.R.; Abu-Rmaileh, R.; Dickinson, P.A.; Abrahamsson, B.; Østergaard, J; Mullertz, A. Oral bioavailability of cinnarizine in dogs: Relation to SNEDDS droplet size, drug solubility and in vitro precipitation. Eur. J. Pharm. Sci. 2013, 48, 339-350. [CrossRef] 
11. Shahba, A.A.-W.; Mohsin, K.; Alanazi, F.K.; Abdel-Rahman, S.I. Optimization of self-nanoemulsifying formulations for weakly basic lipophilic drugs: Role of acidification and experimental design. Br. J. Pharm. Sci. 2016, 52, 654-667. [CrossRef]

12. Jørgensen, S.D.S.; Rades, T.; Mu, H.; Graeser, K.; Mullertz, A. Exploring the utility of the chasing principle: Influence of drug-free SNEDDS composition on solubilization of carvedilol, cinnarizine and R3040 in aqueous suspension. Acta Pharm. Sin. B. 2019, 9, 194-201. [CrossRef]

13. Ilie, A.-R.; Griffin, B.T.; Vertzoni, M.; Kuentz, M.; Kolakovic, R.; Prudic-Paus, A.; Malash, A.; Bohets, H.; Herman, J.; Holm, R. Exploring precipitation inhibitors to improve in vivo absorption of cinnarizine from supersaturated lipid-based drug delivery systems. Eur. J. Pharm. Sci. 2021, 159, 105691. [CrossRef] [PubMed]

14. Shahba, A.A.; Tashish, A.Y.; Alanazi, F.K.; Kazi, M. Combined self-nanoemulsifying and solid dispersion systems showed enhanced cinnarizine release in hypochlorhydria/achlorhydria dissolution model. Pharmaceutics 2021, 13, 627. [CrossRef] [PubMed]

15. Ruether, F.; Sadowski, G. Modeling the solubility of pharmaceuticals in pure solvents and solvent mixtures for drug process design. J. Pharm. Sci. 2009, 98, 4205-4215. [CrossRef]

16. Blagden, N.; De Matas, M.; Gavan, P.; York, P. Crystal engineering of active pharmaceutical ingredients to improve solubility and dissolution rates. Adv. Drug Deliv. Rev. 2007, 59, 617-630. [CrossRef]

17. Kazi, M.; Alhajri, A.; Alshehri, S.M.; Elzayat, E.M.; Al Meanazel, O.T.; Shakeel, F.; Noman, O.; Altamimi, M.A.; Alanazi, F.K. Enhancing oral bioavailability of apigenin using a bioactive self-nanoemulsifying drug delivery system (Bio-SNEDDS): In vitro, in vivo and stability evaluations. Pharmaceutics 2020, 12, 749. [CrossRef] [PubMed]

18. Alshehri, S.; Shakeel, F. Solubility determination, various solubility parameters and solution thermodynamics of sunitinib malate in some cosolvents, water and various (Transcutol + water) mixtures. J. Mol. Liq. 2020, 307, 112970. [CrossRef]

19. Shakeel, F.; Alshehri, S. Solubilization, Hansen solubility parameters, solution thermodynamics and solvation behavior of flufenamic acid in (Carbitol + water) mixtures. Processes 2020, 8, 1204. [CrossRef]

20. Shakeel, F.; Haq, N.; Alanazi, F.K.; Alanazi, S.A.; Alsarra, I.A. Solubility of sinapic acid in various (Carbitol + water) systems: Computational modeling and solution thermodynamics. J. Thermal Anal. Calorim. 2020, 142, 1437-1446. [CrossRef]

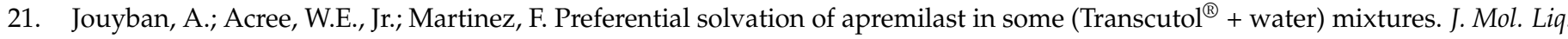
2020, 316, 113905. [CrossRef]

22. Barzegar-Jalali, M.; Agha, E.M.H.; Adibkia, K.; Martinez, F.; Jouyban, A. The solubility of ketoconazole in binary carbitol + water mixtures at $T=(293.2313 .2)$ K. J. Mol. Liq. 2020, 297, 111756. [CrossRef]

23. Osoria, I.P.; Martinez, F.; Pena, M.A.; Jouyban, A.; Acree, W.E., Jr. Solubility of sulphadiazine in some $\left\{\right.$ Carbitol ${ }^{\circledR}(1)+$ water $\left.(2)\right\}$ mixtures: Determination, correlation, and preferential solvation. Phys. Chem. Liq. 2021, 59, 890-906. [CrossRef]

24. Apelblat, A.; Manzurola, E. Solubilities of o-acetylsalicylic, 4-aminosalicylic, 3,5-dinitrosalicylic and p-toluic acid and magnesiumDL-aspartate in water from $\mathrm{T}=(278-348) \mathrm{K} . \mathrm{J}$. Chem. Thermodyn. 1999, 31, 85-91. [CrossRef]

25. Manzurola, E.; Apelblat, A. Solubilities of L-glutamic acid, 3-nitrobenzoic acid, acetylsalicylic, p-toluic acid, calcium-L-lactate, calcium gluconate, magnesium-DL-aspartate, and magnesium-L-lactate in water. J. Chem. Thermodyn. 2002, 34, 1127-1136. [CrossRef]

26. Yalkowsky, S.H.; Roseman, T.J. Solubilization of drugs by cosolvents. In Techniques of Solubilization of Drugs; Yalkowsky, S.H., Ed.; Marcel Dekker Inc.: New York, NY, USA, 1981; pp. 91-134.

27. Akay, S.; Kayan, B.; Jouyban, A.; Martinez, F.; Acree, W.E., Jr. Equilibrium solubility vanillin in some (ethanol + water) mixtures: Determination, correlation, thermodynamics and preferential solvation. J. Mol. Liq. 2021, 342, 117529. [CrossRef]

28. Ruidiaz, M.A.; Delgado, D.R.; Martínez, F.; Marcus, Y. Solubility and preferential solvation of indomethacin in 1,4-dioxane + water solvent mixtures. Fluid Phase Equilib. 2010, 299, 259-265. [CrossRef]

29. Shakeel, F.; Haq, N.; Alshehri, S. Solubility data of the bioactive compound piperine in (Transcutol + water) mixtures: Computational modeling, Hansen solubility parameters and mixing thermodynamic properties. Molecules 2020, 25, 2743. [CrossRef]

30. Shakeel, F.; Alshehri, S.; Haq, N.; Elzayat, E.; Ibrahim, M.; Altamimi, M.A.; Mohsin, K.; Alanazi, F.K.; Alsarra, I.A. Solubility determination and thermodynamic data of apigenin in binary $\left\{\right.$ Transcutol $^{\circledR}+$ water $\}$ mixtures. Ind. Crops Prod. 2018, 116, 56-63. [CrossRef]

31. Shakeel, F.; Haq, N.; Alanazi, F.K.; Alsarra, I.A. Solubility and thermodynamic function of apremilast in different (Transcutol + water) cosolvent mixtures: Measurement, correlation and molecular interactions. J. Ind. Eng. Chem. 2017, 56, 99-107. [CrossRef]

32. Higuchi, T.; Connors, K.A. Phase-solubility techniques. Adv. Anal. Chem. Inst. 1965, 4, 117-122.

33. Shakeel, F.; Haq, N.; Salem-Bekhit, M.M.; Raish, M. Solubility and dissolution thermodynamics of sinapic acid in (DMSO + water) binary solvent mixtures at different temperatures. J. Mol. Liq. 2017, 225, 833-839. [CrossRef]

34. Zhu, Q.N.; Wang, Q.; Hu, Y.B.; Abliz, X. Practical determination of the solubility parameters of 1-alkyl-3-methylimidazolium bromide ([CnClim] Br, $\mathrm{n}=5,6,7,8)$ ionic liquids by inverse gas chromatography and the Hansen solubility parameter. Molecules 2019, 24, 1346. [CrossRef] [PubMed]

35. Alanazi, A.; Alshehri, S.; Altamimi, M.; Shakeel, F. Solubility determination and three dimensional Hansen solubility parameters of gefitinib in different organic solvents: Experimental and computational approaches. J. Mol. Liq. 2020, 299, 112211. [CrossRef]

36. Kalam, M.A.; Alshamsan, A.; Alkholief, M.; Alsarra, I.A.; Ali, R.; Haq, N.; Anwer, M.K.; Shakeel, F. Solubility measurement and various solubility parameters of glipizide in different neat solvents. ACS Omega 2020, 5, 1708-1716. [CrossRef] [PubMed] 
37. Anwer, M.K.; Muqtader, M.; Iqbal, M.; Ali, R.; Almutairy, B.K.; Alshetaili, A.; Alshahrani, S.M.; Aldawsari, M.F.; Alalaiwe, A.; Shakeel, F. Estimating the solubility, solution thermodynamics, and molecular interactions of aliskiren hemifumarate in alkyl imidazolium based ionic liquids. Molecules 2019, 24, 2807. [CrossRef]

38. Wan, Y.; He, H.; Huang, Z.; Zhang, P.; Sha, J.; Li, T.; Ren, B. Solubility, thermodynamic modeling and Hansen solubility parameter of 5-norbornene-2,3-dicarboximide in three binary solvents (methanol, ethanol, ethyl acetate + DMF) from $278.15 \mathrm{~K}$ to $323.15 \mathrm{~K}$. J. Mol. Liq. 2020, 300, E112097. [CrossRef]

39. Mondal, P.; Roy, S.; Loganathan, G.; Mandal, B.; Dharumadurai, D.; Akbarsha, M.A.; Sengupta, P.S.; Chattopadhyay, S.; Guin, P.S. 1-Amino-4-hydroxy-9,10-anthraquinone-An analogue of anthracycline anticancer drugs, interacts with DNA and induces apoptosis in human MDA-MB-231 breast adinocarcinoma cells: Evaluation of structure-activity relationship using computational, spectroscopic and biochemical studies. Biochem. Biophys. Rep. 2015, 4, 321-323.

40. Banerjee, S.; Roy, S.; Datta, A.; Mondal, P.; Mishra, M.; Perumalsamy, B.; Thirmurugan, R.; Dharumadurai, D.; Das, S.; Guin, P.S. Solubilization of sodium 3-amino-2-hydroxyanthraquinone-1-sulfonate in sodium dodecyl sulfate micelles explains its permeation in A549 human lung cancer cell. J. Chin. Chem. Soc. 2021, 68, 250-262. [CrossRef]

41. Krug, R.R.; Hunter, W.G.; Grieger, R.S. Enthalpy-entropy compensation. 2. Separation of the chemical from the statistic effect. J. Phys. Chem. 1976, 80, 2341-2351. [CrossRef]

42. Holguín, A.R.; Rodríguez, G.A.; Cristancho, D.M.; Delgado, D.R.; Martínez, F. Solution thermodynamics of indomethacin in propylene glycol + water mixtures. Fluid Phase Equilib. 2012, 314, 134-139. [CrossRef] 